\title{
Integration of Vision and Vestibular Therapy for Vestibulo-Ocular Post-Concussion Disorder - A Case Study
}

\author{
Lauren Ziaks \\ Intermountain Park City Hospital, Phoenix Concussion Recovery, ziaks.l@gmail.com \\ Rosemary Giardina \\ Clement J. Zablocki VA Medical Center, giardina.30@osu.edu \\ Anne Kloos \\ The Ohio State University Department of Physical Therapy, Anne.Kloos@osumc.edu
}

Follow this and additional works at: https://nsuworks.nova.edu/ijahsp

Part of the Medicine and Health Sciences Commons

\section{Recommended Citation}

Ziaks L, Giardina R, Kloos A. Integration of Vision and Vestibular Therapy for Vestibulo-Ocular PostConcussion Disorder - A Case Study. The Internet Journal of Allied Health Sciences and Practice. 2019 Jan 01;17(3), Article 11.

This Case Study is brought to you for free and open access by the College of Health Care Sciences at NSUWorks. It has been accepted for inclusion in Internet Journal of Allied Health Sciences and Practice by an authorized editor of NSUWorks. For more information, please contact nsuworks@nova.edu. 


\title{
Integration of Vision and Vestibular Therapy for Vestibulo-Ocular Post- Concussion Disorder - A Case Study
}

\begin{abstract}
Purpose: The purpose of this case study was to examine the effectiveness of integrated vision and vestibular therapy for an individual with oculomotor and vestibular system impairments secondary to a concussion further defined as vestibulo-ocular post-concussion disorder. A secondary purpose was to suggest an appropriate timeline to introduce vision therapy and integrate vestibular rehabilitation therapy based on protocol used in an outpatient concussion rehabilitation clinic.

Method This was a case study on a 16-year-old female with protracted concussion recovery. Treatment consisted of 9 in-clinic visits for vision therapy with the final 6 visits addressing vision and vestibular deficits. A home exercise program supplemented the weekly clinic sessions. Outcomes measures included the Activity-Specific Balance Confidence Scale (ABC Scale), Brain Injury Vision Symptom Survey (BIVSS), Convergence Insufficiency Symptom Survey (CISS), Dizziness Handicap Inventory (DHI), and PostConcussion Symptom Scale (PCSS). Improvements in vision and vestibular function were assessed with a comprehensive visuo-vestibular re-evaluation at discharge and 5 month follow up.
\end{abstract}

Results:Improvements in oculomotor control, vergences, vestibular function, and symptomology were reported and measured at discharge and corresponded with clinically meaningful functional outcome improvements. The patient improved from $68 \%$ to $96.88 \%$ on the ABC (

Conclusion: Results from this case study suggest integrated vision and vestibular therapy, when done in the appropriate timeline, may be used to efficiently and effectively manage vestibulo-ocular postconcussion disorder.

Author Bio(s)

Lauren Ziaks, DPT, ATC

After extensive training and a vision therapy mentorship with an Occupational Therapist from the VA network, Lauren created a comprehensive concussion practice in Park City, Utah. She specializes in vision and vestibular rehabilitation therapy for protracted recovery. She is co-founder of phoenixconcussionrecovery.com which provides education and management guidelines for concussion recovery.

Rosemary Giardina, DPT

Rosemary studied under Lauren Ziaks at her concussion practice in Park City, Utah while a student at The Ohio State University. She now practices in neurologic rehabilitation and is completing a neurologic physical therapy residency through Marquette University and the Zablocki VA Medical Center.

Anne Kloos, PT, PhD, NCS

Anne Kloos, PT, PhD, NCS is a Professor in the PT Division at Ohio State University. She teaches adult neurorehabilitation and vestibular rehabilitation courses and conducts clinical research on individuals with neurodegenerative diseases. She's authored a chapter on vestibular/cerebellar disorders in Neurologic Rehabilitation: Neuroscience and Neuroplasticity in Physical Therapy Practice.

\section{Acknowledgements}

We would like to acknowledge our research site Wasatch Physical Therapy \& Sports Medicine for their support in the development of these protocols. Lauren Ziaks was employed at this facility when the study 
was conducted. Rosemary Giardina was on clinical rotation at The Ohio State University when this study was conducted. 


\title{
IIIAHSP \\ The Internet Joumal of Allied Health Sciences and Practice
}

Dedicated to allied health professional practice and education

Vol. 17 No. 3 ISSN 1540-580X

\section{Integration of Vision and Vestibular Therapy for Vestibulo-Ocular Post- Concussion Disorder - A Case Study}

\author{
Lauren Ziaks ${ }^{1}$ \\ Rosemary Giardina ${ }^{2}$ \\ Anne Kloos 3 \\ 1. Intermountain Park City Hospital \\ 2. Clement J. Zablocki VA Medical Center \\ 3. The Ohio State University \\ United States
}

\begin{abstract}
Purpose: The purpose of this case study was to examine the effectiveness of integrated vision and vestibular therapy for an individual with oculomotor and vestibular system impairments secondary to a concussion further defined as vestibulo-ocular postconcussion disorder. A secondary purpose was to suggest an appropriate timeline to introduce vision therapy and integrate vestibular rehabilitation therapy based on protocol used in an outpatient concussion rehabilitation clinic. Method This was a case study on a 16-year-old female with protracted concussion recovery. Treatment consisted of 9 in-clinic visits for vision therapy with the final 6 visits addressing vision and vestibular deficits. A home exercise program supplemented the weekly clinic sessions. Outcomes measures included the Activity-Specific Balance Confidence Scale (ABC Scale), Brain Injury Vision Symptom Survey (BIVSS), Convergence Insufficiency Symptom Survey (CISS), Dizziness Handicap Inventory (DHI), and Post-Concussion Symptom Scale (PCSS). Improvements in vision and vestibular function were assessed with a comprehensive visuo-vestibular reevaluation at discharge and 5 month follow up. Results: Improvements in oculomotor control, vergences, vestibular function, and symptomology were reported and measured at discharge and corresponded with clinically meaningful functional outcome improvements. The patient improved from $68 \%$ to $96.88 \%$ on the ABC (<67\% indicates fall risk) 78 to 14 on the DHI (MDC 17.18 points, MDIC 18 points); and 46 points to 10 points on the PCSS (MCID 6.8 points). Improvements were maintained at 5 month follow up, despite occurrence of two subsequent subconcussive head injuries. The patient reported improvements in participation in social activities and academic performances at follow up. Conclusion: Results from this case study suggest integrated vision and vestibular therapy, when done in the appropriate timeline, may be used to efficiently and effectively manage vestibulo-ocular post-concussion disorder.
\end{abstract}

Keywords: concussion, protracted recovery, post-concussive, vestibular, oculomotor 


\section{INTRODUCTION}

The Centers for Disease Control (CDC) estimates that 3.6 million concussions occur per year in the United States. Not all concussions are detected or reported, so the actual incidence is suspected to be higher. ${ }^{1}$ Approximately $65 \%$ of concussions occur in the pediatric and adolescent populations. ${ }^{1}$ A concussion is a mild traumatic brain injury (mTBI) that involves a complex pathophysiological process resulting from biomechanical forces acting on the brain. The result of such biomechanical forces leads to altered autonomic nervous system function, cerebral blood flow, and cardiac rhythm. ${ }^{2}$ These nervous system changes cause a variety of functional impairments which prevent individuals from participating in life and social roles regardless of age.

Sports are the second leading cause of traumatic brain injuries for individuals between the ages of 15-24 years. ${ }^{3}$ Approximately $80-85 \%$ of athletes who sustain concussions are asymptomatic within the first 2 weeks and are able to follow graded return to sport and return to learn programs. ${ }^{4}$ Research shows that inactivity and prolonged rest can induce symptoms of fatigue, anxiety, and depression in addition to physical deconditioning, which may further delay recovery in these individuals. ${ }^{2,5}$ Current treatment recommendations for the $15-20 \%$ of individuals with protracted recovery include: rest, education, cognitive behavioral training, neurocognitive rehabilitation, medication, and symptom-based graded return to activity and learn programs.

Emerging research suggests concussion treatment should be individualized based on objective findings as well as an individual's symptomatology. Three potential post-concussion symptom clusters or post-concussion disorders (PCD) have been identified: pathophysiologic, cervicogenic, and vestibulo-ocular. ${ }^{4}$ However, further research is needed to validate each PCD. Pathophysiologic PCD is characterized by headaches exacerbated by physical and cognitive tasks with abnormal heart rates at rest and while exercising. ${ }^{4}$ Cervicogenic PCD is characterized by decreased cervical range of motion and proprioception as well as headaches exacerbated by cervical movement secondary to musculoskeletal injury. ${ }^{4}$ Vestibulo-ocular PCD is characterized by symptoms of vertigo/dizziness, postural and gait instability, and visual disturbances such as motion sensitivity, eye strain/ache, loss of place when reading, headache exacerbated by vestibulo-ocular activities including reading, and difficulty concentrating.4,6 Symptoms such as dizziness, difficulty concentrating, headaches nausea, and photophobia often overlap with pathophysiologic PCD resulting in the frequent misdiagnosis of vestibulo-ocular PCD for pathophysiologic PCD. Misdiagnosis may further be related to the lack of visual symptom assessment with common sideline and initial diagnostic tests supporting the need for vision specific testing when evaluating an individual with $\mathrm{mTBI} .{ }^{7-10}$ Studies have suggested adding the King-Devick test to sideline concussion diagnostic tests as it can indicate oculomotor dysfunction and increase initial detection of concussion. ${ }^{7,11}$

Ellis and colleagues suggest asking questions regarding vision specific symptoms during the subjective portion of the initial evaluation. Should oculomotor deficits be suspected a thorough vision evaluation should be performed by a qualified healthcare professional. An initial vision evaluation should include tests for visual acuity, visual fields, pupillary function, eye movement function, cover/uncover tests for ocular alignment, convergence/vergence tests, smooth pursuits, and vestibular-ocular reflex function. ${ }^{4}$ Common visual dysfunctions include accommodative insufficiency (Al), convergence insufficiency $(\mathrm{Cl})$, and oculomotor dysfunction. ${ }^{12,13}$ Studies suggest $62.5-69 \%$ of adolescents experience at least one and $46 \%$ had more than one of the three above dysfunctions. ${ }^{6}$

Al is the limited ability to focus far to near, effecting academic performance such as the ability to take notes, athletic performance, driving, and gross and fine motor skills. $\mathrm{Cl}$ is a result of impaired motor control occurring when the eyes turn out during near work due to a decreased ability to move the eye or eyes inward. $\mathrm{Cl}$ impairs stereopsis, the ability to perceive three dimensional images and depth. ${ }^{14,15}$ Symptoms associated with $\mathrm{Al}$ and $\mathrm{Cl}$ include headaches, eyestrain, reading problems, the perception of print moving or shimmering, difficulty with close work, and fatigue.14,15 Oculomotor dysfunctions are divided into three categories: fixation, pursuits, and saccades. Individuals with inadequate visual fixation demonstrate difficulty focusing their eyes on a target and may appear inattentive or impulsive. Impaired pursuits present as the inability to accurately and clearly follow a moving object with the eyes. Saccadic deficits occur when the accuracy and speed of eye movements are reduced. Symptoms associated with oculomotor dysfunction include excessive head movement, frequent loss of place or skipping lines during reading, poor attention span, increased time during copying and note-taking tasks, and difficulty with functional tasks such as driving. Individuals with oculomotor dysfunction may present with nystagmus, which is the involuntary, rhythmic oscillation of one or both eyes. If nystagmus is present in the absence of an oculomotor dysfunction, then an individual should be evaluated for a sensory disorder or visual acuity impairment. $\mathrm{Al}, \mathrm{Cl}$, and oculomotor dysfunction cause difficulty in participation in skilled rehabilitation and therapies. ${ }^{6}$ Thus, evaluation and treatment of the visual system by a trained professional is imperative to include in the plan of care with an individual post $\mathrm{mTBI} .6,7,11-15,28,36,38,39$

(C) The Internet Journal of Allied Health Sciences and Practice, 2019 
Extensive research documents vestibular deficits including benign paroxysmal positional vertigo (BPPV) and vestibulo-ocular reflex (VOR) impairments in individuals with mTBI.5,16,17 Symptoms associated with BPPV include intermittent and position specific dizziness, nausea, and gait instability. Symptoms associated with VOR dysfunction include gaze nystagmus, decreased visual acuity, and gait instability. ${ }^{16,17}$ Screening of the vestibulo-ocular system is imperative to include following a concussion and tests for BPPV and VOR function should be included.

It has been hypothesized that each of the three PCD disorders should be treated differently according to the patient's primary impairments. However, limited research exists to support this hypothesis. One research study found that when individuals were treated for the correct type of PCD, which was determined based on symptom clusters, there was an $88 \%$ symptom improvement and average 9 point improvement (MCID 6.8 points) on the Post-Concussion Symptom Scale (PCSS). ${ }^{5}$ The patient discussed in this article presented with symptoms that classified as vestibulo-ocular PCD, which is typically managed with vision therapy, vestibular rehabilitation therapy, a graded aerobic exercise program, and school/work accommodations. ${ }^{4}$ The purpose of this retrospective case study was to examine the effectiveness of integrated vision and vestibular therapy, visuo-vestibular therapy, in a case consistent with vestibulo-ocular PCD. A secondary purpose was to suggest the appropriate timeline for these interventions based on outcomes in this clinic, which averages 200 patients per year. Information from this case study may assist clinicians in their decision-making regarding the timing of interventions for patients with similar presentations (Figure 1).

\section{Patient Presentation}

A 16-year-old female with a history of obsessive-compulsive disorder (OCD) presented to an outpatient concussion rehabilitation clinic with the following symptoms: blurred vision and constant headaches exacerbated by close work (i.e. reading, computer use), tasks requiring increased concentration, and screen time; eye strain with reading; dizziness and a feeling of lightheadedness exacerbated with increased head movements; tinnitus exacerbated by busy environments; and neck pain. She reported a history of sustaining an initial mTBI while water tubing followed by four additional subconcussive incidents in the 3.5-week interval between her initial injury and her arrival at the clinic.

The patient had been cleared by a neuropsychologist to begin a return to learn program. Her school accommodations included wearing sunglasses and earplugs constantly to diminish sensory overload, early leave from classes to avoid crowded hallways, seating in a quiet area for lunch, $50 \%$ of normal homework, 5 minutes of rest per hour, limited use of screens, and utilization of audiobooks instead of reading. The patient had adopted a consistent early bed time. She had already visited an optometrist. She was also seeing an orthopedic physical therapist for cervical spine impairments; the details of this treatment were not made available to the authors.

The physical therapist, who had specialized training in the treatment of individuals with concussions including vision therapy under the direction of a neuro-optometrist, and vestibular rehabilitation therapy, hypothesized that the patient's subjective history was consistent with the mechanism of injury, symptoms, and signs of vestibulo-ocular PCD. Prior to screening other systems, cervical screening tests were performed with no significant findings. An examination for BPPV was not required at initial evaluation due to the absence of subjective complaints consistent with position dependent dizziness. Due to the length of time since injury and the patient's visual complaints, a visual exam was completed at the initial evaluation.

\section{Vestibular and Vision Examination}

The vision evaluation included assessment of convergence, eye alignment, pursuits, saccades, and stereopsis (Table 1). Results demonstrated impairments in oculomotor control and vergence. Additional evaluative and objective measures were obtained through the Binocular Vision Assessment (BVA) computerized program the visit immediately following this visuo-vestibular screen (Table 2). Measurements obtained from the BVA objectively confirmed oculomotor deficits noted upon initial evaluation. Vestibular testing included static balance testing without the visual system (Table 3) and VOR assessment (Table 1). Balance testing, the Balance Error Scoring System (BESS) and Rhomberg tests, showed impairments in proprioception and vestibular function. VOR assessment indicated impairments in gaze stability and VOR cancellation with positive >3-point symptom provocation of dizziness and headache at $<60$ beats per minute. The successive subconcussive blows that occurred after the initial injury, possibly secondary to poor body awareness and perception, likely caused the severity of her symptoms present at her physical therapy evaluation. Her symptoms of headaches, difficulty concentrating, and blurred vision prevented her from full participation in school, theater, and other social activities. The therapist recommended skilled physical therapy to address balance, oculomotor, and visuovestibular impairments to return to school and other recreational and sports activities. 
Table 1: Physical Oculomotor Examination Findings:

\begin{tabular}{|c|c|c|c|c|c|c|}
\hline Test Performed & $\begin{array}{l}\text { Initial } \\
3.5 \text { weeks PI }\end{array}$ & $\begin{array}{l}\text { Subjective } \\
\text { Complaints }\end{array}$ & $\begin{array}{l}\text { Discharge } \\
15.25 \text { weeks } \\
\text { PI }\end{array}$ & $\begin{array}{l}\text { Subjective } \\
\text { Complaints }\end{array}$ & $\begin{array}{l}5 \text { Month } \\
\text { Follow Up } \\
37.5 \text { Weeks } \\
\text { PI }\end{array}$ & $\begin{array}{l}\text { Subjective } \\
\text { Complaints }\end{array}$ \\
\hline Pursuits & $\begin{array}{l}\text { "Fair-good": } \\
\text { poor cervical- } \\
\text { ocular } \\
\text { dissociation. } \\
\text { R>L mild } \\
\text { nystagmus, } \\
\text { horizontal } \\
\text { midline catch. }\end{array}$ & $\begin{array}{l}\text { Effortful, eye } \\
\text { strain, } \\
\text { headache, } \\
\text { intermittent } \\
\text { diplopia }\end{array}$ & WNL & & WNL & \\
\hline Saccades & $\begin{array}{l}\text { "Fair": poor } \\
\text { cervical-ocular } \\
\text { dissociation. } \\
R>L \text { mild } \\
\text { nystagmus in } \\
\text { all directions. }\end{array}$ & & $\begin{array}{l}\text { Mild } \\
\text { nystagmus, } \\
\text { WFL }\end{array}$ & & $\begin{array}{l}\text { Mild } \\
\text { nystagmus } \\
\text { WFL }\end{array}$ & \\
\hline NPC* & $\begin{array}{l}12.7 \mathrm{~cm}, \mathrm{R} \\
\text { nystagmus }\end{array}$ & & & $\begin{array}{l}\text { No symptoms, } \\
\text { diplopia, or } \\
\text { nystagmus. }\end{array}$ & & $\begin{array}{l}\text { No symptoms, } \\
\text { diplopia, or } \\
\text { nystagmus. }\end{array}$ \\
\hline Brock string & $35.56 \mathrm{~cm}$ & $\begin{array}{l}\mathrm{R} \text { nearfield } \\
\text { suppression }\end{array}$ & $\begin{array}{l}6.35-122 \mathrm{~cm}, \\
\text { WFL }\end{array}$ & $\begin{array}{l}\text { R nearfield } \\
\text { suppression } \\
<5 \mathrm{~cm}\end{array}$ & $\begin{array}{l}7.62 \mathrm{~cm}, \\
\text { WFL }\end{array}$ & \\
\hline Stereopsis & $\begin{array}{l}\text { Correct but } \\
\text { delayed }\end{array}$ & & WNL & & WNL & \\
\hline Cover/uncover & $\begin{array}{l}\text { R: intermittent } \\
\text { inward } \\
\text { movement } \\
\text { L: WNL }\end{array}$ & & WNL & Mild headache & WNL & No headache \\
\hline Alternate cover & $\begin{array}{l}\mathrm{R}: \text { inward } \\
\text { movement }\end{array}$ & & WNL & & WNL & \\
\hline VOR x1/x2 & Slow & $\begin{array}{l}\text { Headache, } \\
\text { dizziness }\end{array}$ & $56 / 25 \mathrm{bpm}$ & \multirow{2}{*}{$\begin{array}{l}\text { Seated: } \\
\text { provoked } \\
\text { dizziness, } \\
\text { headache }\end{array}$} & $90 / 65 \mathrm{bpm}$ & \multirow{2}{*}{$\begin{array}{l}\text { Standing: mild } \\
\text { oscillopsia, } \\
\text { minimal } \\
\text { headache, } \\
\text { yaw>pitch }\end{array}$} \\
\hline VOR Cancellation & Slow & Mild dizziness & 25 bpm & & 65 bpm & \\
\hline
\end{tabular}

PI - post injury. R - right. L - left. WFL - within functional limits. WNL - within normal limits.

${ }^{*} \mathrm{NPC}$ - near point convergence, normal is within $6 \mathrm{~cm} .{ }^{14,16,17}$ 
Table 2: Binocular Vision Assessment (BVA)

\begin{tabular}{|l|l|l|l|}
\hline & Initial $\mathbf{- 3 . 5}$ weeks post injury & $\begin{array}{l}\text { Discharge - 15.5 weeks } \\
\text { post injury }\end{array}$ & $\begin{array}{l}\mathbf{5} \text { Month Follow Up - 37.5 } \\
\text { weeks post injury }\end{array}$ \\
\hline Phoria & Ortho & .86 eso & Ortho \\
\hline Fusional Range & $-19 / 8$ to $+55 / 17$ & $-17 / 4$ to $+59 / 59$ & $-23 / 15$ to $+59 / 59$ \\
\hline Saccades & $\begin{array}{l}96.5 \% \text { accurate, } .69 \text { second } \\
\text { reaction time }\end{array}$ & $\begin{array}{l}98.82 \% \text { accurate, } .71 \text { second } \\
\text { reaction time }\end{array}$ & $\begin{array}{l}95.45 \% \text { accurate, } .69 \text { second } \\
\text { reaction time }\end{array}$ \\
\hline
\end{tabular}

Normal fusional range: $-18 \boldsymbol{\nabla}+30$. Saccades: Normal accuracy $>95 \%$ and reaction time $.6-.7$ seconds.

\section{Table 3: Vision Removed Balance Assessments}

\begin{tabular}{|l|l|l|l|}
\hline & $\begin{array}{l}\text { Initial - 3.5 weeks post } \\
\text { injury }\end{array}$ & $\begin{array}{l}\text { Discharge - 15.25 weeks } \\
\text { post injury }\end{array}$ & $\begin{array}{l}\mathbf{5} \text { Month Follow Up - 37.5 } \\
\text { weeks post injury }\end{array}$ \\
\hline Rhomberg & Mild-moderate lateral sway & WNL & WNL \\
\hline Tandem L Forward & 3 errors & 1 error - WFL & 1 error - WFL \\
\hline Tandem R Forward & 4 errors & 1 error - WFL & WNL \\
\hline L Single Leg Stance & 4 errors & Not assessed & 3 errors \\
\hline R Single Leg Stance & 3 errors & Not assessed & 1 error - WFL \\
\hline
\end{tabular}

WNL - within normal limits. WFL - within functional limits.

Balance testing errors were defined as any compensatory arm movement, trunk lean, corrective hip response, or corrective stepping response consistent with Balance Error Scoring System (BESS) testing.

\section{Outcomes}

Outcome assessments administered on initial evaluation include the Activities-Specific Balance Confidence (ABC) Scale ( $<67 \%$ indicates fall risk in this population); 21 the Brain Injury Vision Symptom Survey (BIVSS, MDC/MCID not yet established); the Convergence Insufficiency Symptom Survey (CISS, MDC/MCID not yet established); Dizziness Handicap Inventory (DHI, 17.18 points MDC, 18 points MCID) 22; and the Post-Concussion Symptom Scale (PCSS 6.8 points MCID). The ABC has good reliability and validity at predicting falls in the brain injury population. ${ }^{21,22}$ The CISS has been validated and deemed reliable for individuals with brain injury between the ages of 9 and 18 , with scores $>16$ significant for $\mathrm{Cl}$ related symptoms. ${ }^{23}$ The BIVSS is a newer outcome measure and now includes the CISS. A preliminary study determining the validity of the BIVSS found it to be $82.2 \%$ sensitive for predicting TBI. The DHI is a recommended outcome measure by the TBI EDGE taskforce. ${ }^{21,24}$ The validity and reliability in the PCSS have yet to be established. However, one study found a $40.81 \%$ sensitivity (which increases by about $24.41 \%$ when used in conjunction with computerized neurocognitive testing) and $79.31 \%$ specificity in predicting recovery. ${ }^{25}$ Outcome scores are detailed in Figure 1. 


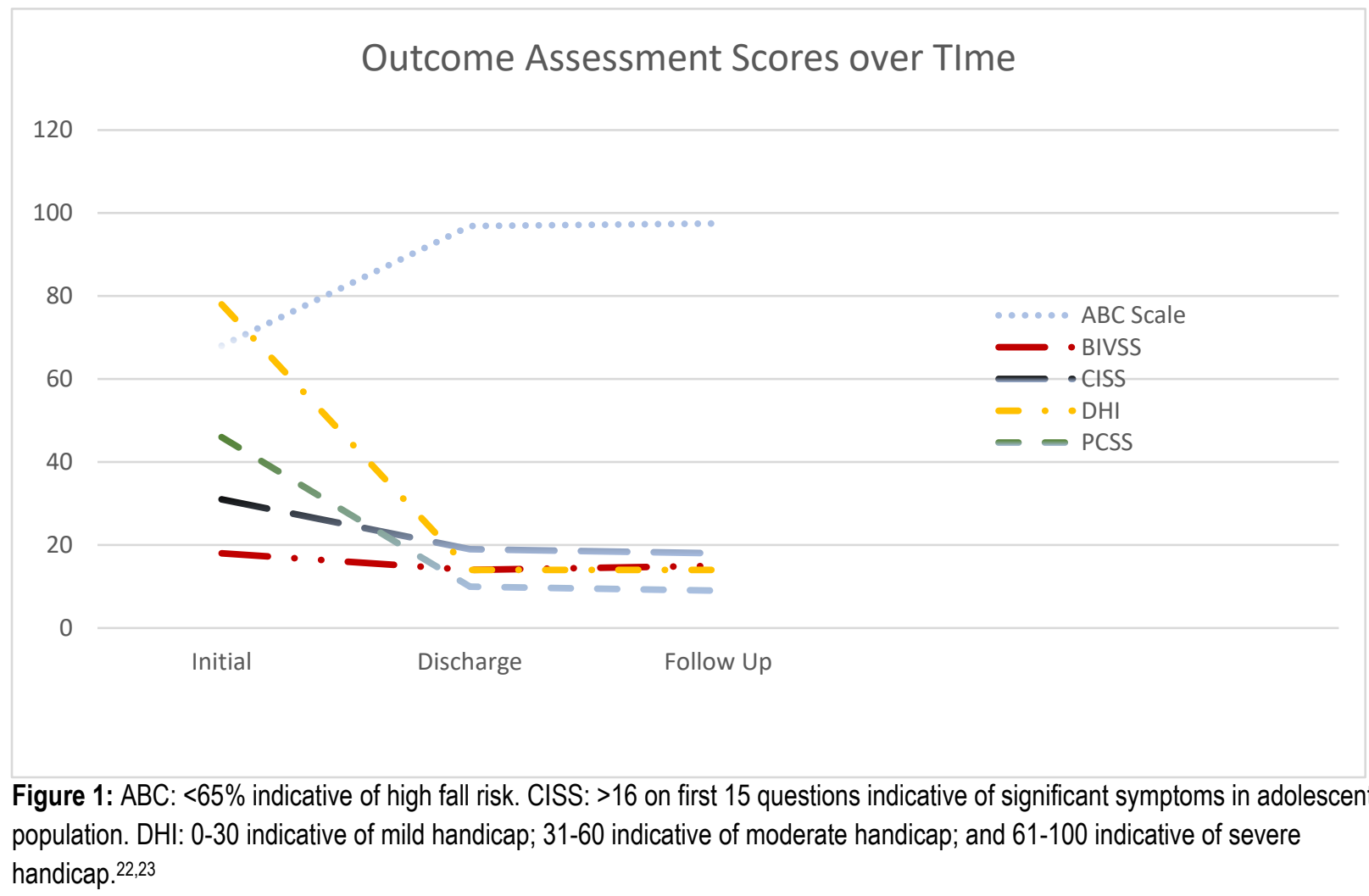

\section{INTERVENTION}

The initial long-term goals established by the evaluating physical therapist were created with a 6-week minimum timeframe with consideration of the patient's goals and life-roles. Predictive factors of protracted recovery, in this case, included: severity of symptoms, history of OCD, potential history of subconcussive brain injuries, motion intolerance at baseline, gender, blurred vision, difficulty focusing, and dizziness within the first few days of injury. 8,20 Positive prognostic factors included absence of amnesia with incident; absence of pre-morbid depression, learning disability, sleep disorder, migraine, or ADD/ADHD. ${ }^{8}$ The plan of care initiated for this patient included physical therapy for vision therapy, balance re-training, and vestibular rehabilitation. The patient was instructed to begin a daily light aerobic exercise program (20-40 minutes of walking/day at a 5/10 effort) at home to facilitate brain healing and restore appropriate autonomic nervous system function. ${ }^{18,19}$ Cervical spine interventions were not included in the plan of care as treatment was completed at a more convenient location for the patient and the treatment details were not made available to the authors. The significant binocular vision deficits (brock string near point convergence $>25 \mathrm{~cm}$ ) required the therapist to refer to the supervising Doctor of Optometry (OD) for a comprehensive neuro-optometric exam. This referral was required per the established relationship between the $\mathrm{OD}$ and PT, however, therapy was able to continue as the patient awaited further examination.

The patient was scheduled to be seen once a week for 4-6 weeks with a planned decline in frequency to 2 times per month for the following 1-2 months. Each visit included 10 minutes of history regarding the prior week and 20 minutes of pulsed vision therapy supervised by the therapist followed by 30 minutes of pulsed progressive exercises from balance to habituation to advanced visuovestibular therapy supervised one-on-one by a trained aide prescribed by the therapist. The patient was provided with verbal and written home exercise program (HEP) instructions to perform each day outside of therapy in 2, 15 minute sessions for a total of 30 minutes per day. The appropriate frequency and intensity of training for the most efficient and effective recovery from vestibulo- 
ocular PCD vary within the literature. ${ }^{26,27}$ The frequency used in this case was similar to one utilized by Gallaway and colleagues for treatment of individuals with post-concussion vision disorders. They recommended a frequency of office visits 1-2 times per week with a HEP to be performed for 15 minutes per day, $3-5$ times per week. ${ }^{28}$ The HEP required 30 minutes as it combined vision and vestibular rehabilitation, each requiring exercises specifically targeted to these deficits. This extensive home program allowed for a limited number of visits, which decreased cost to the patient, and achievement of clinically meaningful improvements.

Interventions utilized for this individual were categorized as vision, vestibular, and integrated visuo-vestibular therapy. Vision therapy consisted of interventions to improve neuromuscular activation, control, and endurance of oculomotor muscles. These interventions could further be categorized as vision exercises for smooth pursuits, saccades, complex tasks, and vergence. Research supports saccadic and smooth pursuit training prior to addressing impairments with vergence and accommodation for individuals post $\mathrm{mTBI}$ who present with vestibulo-ocular dysfunction..$^{14,29}$ Individuals who have incurred a mTBI often have tunneling or peripheral vision loss. ${ }^{30}$ Thus, interventions designed to facilitate improvement in peripheral vision were also included early on in this patient's plan of care. As tolerance to vision therapy improved, convergence and accommodation interventions were integrated into the plan of care on the $4^{\text {th }}$ visit. These authors have observed it is best to wait 3-6 weeks before initiating vergence exercises, as they are more complex and require basic oculomotor control. ${ }^{14}$ Vestibular interventions included proprioception training and VOR training for gaze stability with intent to improve residual dizziness and balance impairments. ${ }^{17}$ Similar to vergence training, habituation therapy such as VOR exercises were not added until after the $3^{\text {rd }}$ week of vision therapy. The authors have found VOR interventions are tolerated better and are more effective after 2-4 weeks of oculomotor saccadic and pursuit training for individuals with impairments in both systems. Thus, balance training interventions designed to address substitution for the vestibular system without head movement supplemented the first three weeks of this patient's vision therapy.

\section{Vision Exercise Program}

Early vision interventions focused on saccades and smooth pursuits. The patient was provided with demonstration and written directions for the correct performance of each exercise in her initially prescribed HEP (Figure 2). Initial vision exercises were added in the 1 st-3rd follow up visits:

\section{Saccades}

Super saccades with targeted movements vertical and horizontal with a goal of 30-35 seconds were implemented. The patient was instructed to progress at home from seated to standing to marching in place with the timed goal remaining constant. Alphabet saccades for scanning required the patient to underline the pre-determined letter from right to left with a goal of 60 seconds without errors. The patient was instructed to continue this exercise until she achieved the goal.

\section{Anti-suppression Scanning Exercises}

Exercises were targeted to improve suppression were completed with red/green glasses. A page with red letters and green numbers was provided and the patient marks first the letters followed by the numbers allowing for comparison between left and right eyes. The goal for this exercise is 60 seconds for 26 items. At home, the patient was instructed to complete alternate patched exercises (pinwheel and alphabet saccades) followed by 1 repetition of the exercise binocular to improve suppression.

\section{Peripheral Awareness Exercises}

Each patient completed a catch and throw exercise that utilized peripheral vision to improve awareness. A cognitive load or unstable surface was added as tolerated to progress the challenge of this exercise. 


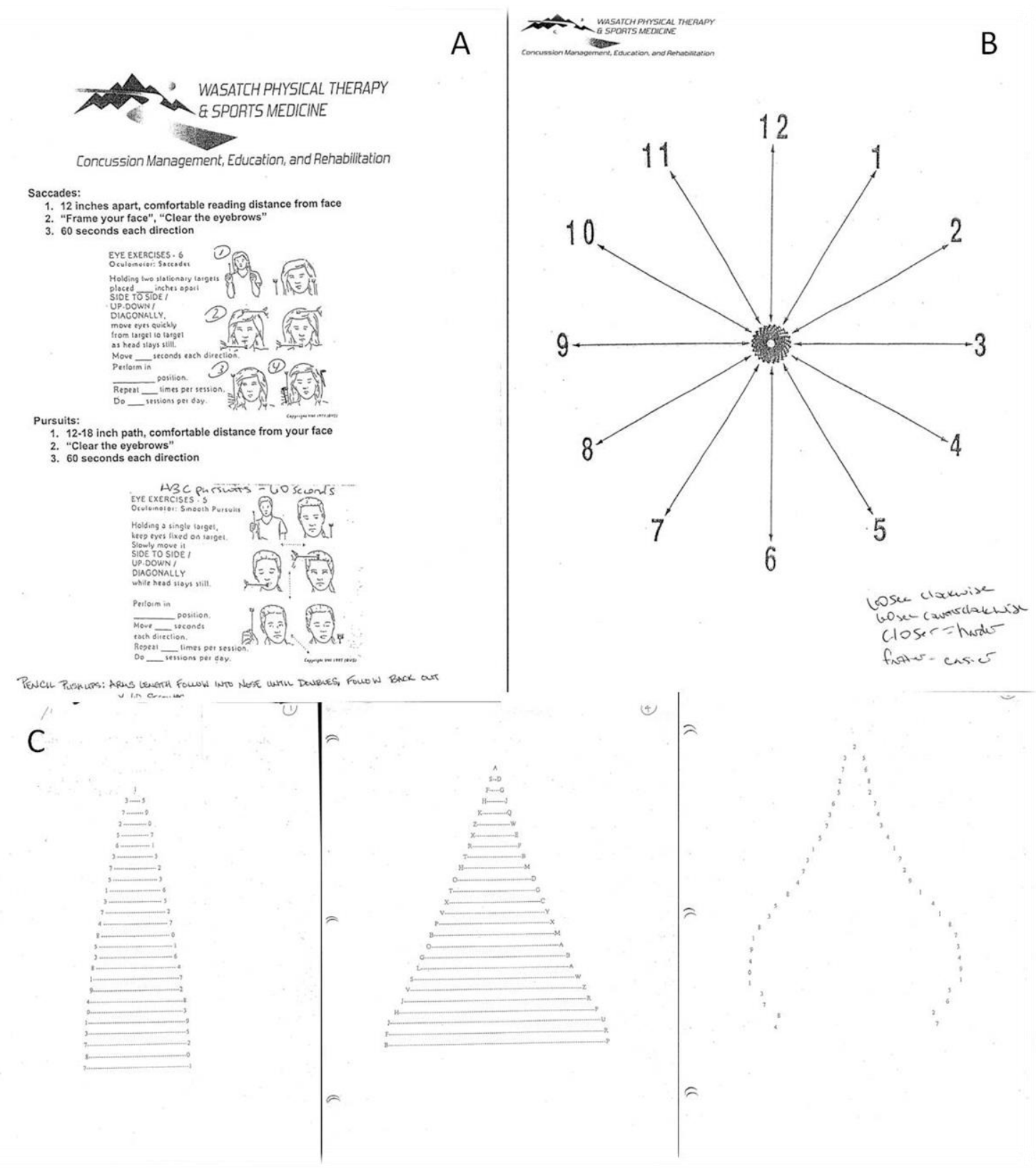

Figure 2. Initial home exercise program: Example of an initial HEP to address oculomotor control for saccades, pursuits and pencil pushups for initial abduction and adduction control. All exercises were progressed from seated to standing to marching in place prior to discontinuing the exercise. A: The patient was instructed to complete pencil saccades, pencil pursuits, and pencil pushups for a duration of 60 seconds per direction for a total of 9 minutes. B: Pinwheel - the patient completed monocular (one eye) for 2 minutes, switched eyes, and then completed binocular for a total of 6 minutes. The eyes are moved from center to the number and back smoothly following the line. C: Line reading - A progression of 8 pages increasing in difficulty is provided. These are a sample of 3 pages each with the goal of $15-20$ seconds per page with the patient progressing as tolerated. 
In the fourth to eighth follow up visits, interventions that trained convergence and accommodation were added. These interventions included the Brock String and Hart Chart amongst others. Caution should be exercised when addressing binocular vision disorders in the clinic due to the risk of harm to patients when completed incorrectly or prior to establishing basic oculomotor control. It is possible to increase symptoms, suppression, or cause convergence excess or spasm when these higher-level exercises are completed inappropriately:

\section{Balance Training}

Balance training was included in the first follow up visit with obstructed vision via glasses progressing to eliminated vision to better train the vestibular system. Interventions included ladder drills with dual tasks as well as timed eyes closed weight shifts, lunges, and step-ups to non-compliant surfaces. A dual task or cognitive load such as serial $3 \mathrm{~s}$ or categories were added to further challenge the system.

Initial integrated Visuo-vestibular Exercises

Initial integrated visus-vestibular exercises combined scanning vision exercises (2 vertical strips with letters) with a secondary task such as: stepping up and over on an unstable surface, standing on a narrow base of support, or while performing a secondary motor task or cognitive load. Exercises were completed $\times 30-60$ seconds per repetition with rest as required following each repetition. Vestibular and visuo-vestibular exercises often provoked symptoms of dizziness, headache, and fatigue within a controlled range ( $<3 / 10$ symptom exacerbation). This was the desired effect, as research shows symptom provocation within a recoverable range facilitates habituation and expedites recovery. ${ }^{16}$ The authors define a recoverable range as symptom exacerbation no greater than $2-3 / 10$ points.

Yaw and Pitch

Horizontal (yaw) and vertical (pitch) VOR $x 1$ and $\times 2$ exercises were initiated on the $4^{\text {th }}$ week of vision therapy. VOR $x 1$ was tolerated at 60 beats per minute $(\mathrm{bpm})$ pitch and $65 \mathrm{bpm}$ yaw. VOR $\times 2$ was tolerated at $80 \mathrm{bpm}$ pitch and $65 \mathrm{bpm}$ yaw. She received written instructions to add these exercises to her HEP. She was instructed to progress to 1.5 cycles per second (cps) or $90 \mathrm{bpm}$ for VOR $\mathrm{x} 1$ and 70-90 bpm for VOR $\mathrm{x} 2$ (the equivalent of $3 \mathrm{cps}$ on VORx1). This frequency was calculated from studies indicating $2-3 \mathrm{~Hz}$ as normal VOR function. ${ }^{31-33}$ The patient was educated on the appropriate amount of symptom provocation and when to progress from seated to standing. Once improvement in VOR function occurred, more challenging visuo-vestibular interventions were incorporated such as walking with head turns and saccades with 90-degree head turns.

\section{RESULTS}

Vision therapy began 3.5 weeks post mTBI. The patient's frequency of physical therapy was decreased to bimonthly after her $6^{\text {th }}$ visit (9.4 weeks from injury) and was discharged after her $9^{\text {th }}$ visit (15.25 weeks from injury). A detailed history was recorded at each visit to assess the effectiveness of treatment, determine appropriate therapeutic exercise progression, and measure improvements in participation and life roles. Initial progress felt delayed to the patient reporting on the $3^{\text {rd }}$ visit she felt her "concussion symptoms have hit a plateau." However, she reported "turning a corner" on the $4^{\text {th }}$ visit and was "happy to increase social activity." After 6 visits, she reported "finally feeling good" and no longer needed to wear sunglasses or earplugs in school. By discharge, she was able to increase her participation in social and physical activities, including attendance to football games and participation in dance. Although driving and reading still increased headaches, her tolerance had improved in both activities. She was tolerating increased screen time with the use of anti-fatigue lenses, which had been prescribed by the neuropsychologist, with minimal headache exacerbation. The patient did not experience any additional brain injuries or adverse events not accounted for by her concussion over the course of her therapy.

A complete vision and vestibular re-evaluation was performed on her $9^{\text {th }}$ visit. The patient presented with near resolution of oculomotor and vestibular impairments and improvements in all outcome measures at the time of discharge. Clinically meaningful improvements were noted, as she achieved scores well above the MCIDs and MDCs in the ABC (68\% to $96.88 \%)$, DHI (78\% to $14 \%$ ), and PCSS (46 points to 10 points). While MCIDs and MDCs have not yet been established, the patient did improve from 18 points to 14 points on the BIVSS and from 31 points to 19 points on the CISS. However, she continued to demonstrate mild deficits

(C) The Internet Journal of Allied Health Sciences and Practice, 2019 
with saccades and vergences with signs of central vestibular pathology (Figure 3, Tables 1-3). As previously mentioned, her endurance with driving, reading, and computer tasks was limited but expected to improve over time with increased exposure. The patient had a 504 plan for school accommodations and was still unable to participate in sports or theater to the extent she was able to prior to mTBI. She was discharged after 9 visits (15.25 weeks post-injury) with HEP instructions for the next 4-6 weeks to address her remaining deficits.

The patient presented to the concussion clinic for a short term follow up approximately 5 months after discharge (approximately 6.5 months post $\mathrm{mTBI}$ ). She was no longer using her 504 school accommodations or wearing the antifatigue glasses and reported she was "doing everything normally." She was taking accelerated college level courses and was earning A's in all her classes. Despite daily headaches of 1.5-2/10 intensity, she could participate in an entire play rehearsal without "thinking about my head." She was able to go on her school field trip to an amusement park and tolerated the roller coasters with a minimally increased headache at the end of the day. Driving required increased focus compared to before her initial head injury. Reading was still effortful, and she reported difficulty with comprehension, although this was a pre-morbid challenge and thus may not be solely from her head injury. A comprehensive vision and vestibular re-evaluation was performed (Figure 3, Tables 1-3) at follow-up. Results showed significant improvement in fusional ranges and VOR gain due to continued independent HEP. The patient reported two additional head injuries between the time of discharge and follow up and was no longer adherent to her HEP.

\section{DISCUSSION}

The patient in this retrospective case study presented with impairments in static balance, accommodation, stereopsis, VORs, and oculomotor saccades and smooth pursuits. She was experiencing frequent headaches and dizziness, amongst other symptoms, which were exacerbated with testing at the time of the initial physical therapy evaluation. After 9 physical therapy visits, objective findings had improved to be within normal, functional limits (Tables1-3). Mild symptoms were provoked with VOR cancellation and minimal errors with static balance testing persisted.

This case study supports the evaluation and treatment of the visual system, in addition to the vestibular and balance systems, for an individual with protracted recovery with symptoms consistent with vestibulo-ocular PCD. With the appropriate timing of interventions (Figure 1), collaboration with a neuropsychologist who prescribed antifatigue lenses, and initiation of a return to learn program, the patient returned to life roles and improved social participation in less than 4 months. Subjective improvements were corroborated with numerous outcome measures and objective findings from the vision and vestibular examinations that were readministered at discharge. More importantly, these improvements were maintained at the 5 month follow up, despite the patient incurring two subsequent potential head injuries after discharge. Her recovery suggests that with appropriate interventions and administration, common lasting impairments with learning and difficulties with concentration often reported following concussion may be deferred. It also shows that recovery can be maintained even with subsequent head injuries, suggesting the occurrence of true neuroplastic changes to the vision and vestibular systems.

When symptoms consistent with vestibulo-ocular PCD are identified, a multidisciplinary approach including a medical provider trained to perform a comprehensive vision screen is important for patient recovery. 28,37 Collaboration between providers, occupational therapists and physical therapists, capable of performing vision and vestibular rehabilitation therapy in the appropriate timeframe may improve patient outcomes. These authors also collaborate with optometrists, physician assistants, physicians and neuropsychologists to provide comprehensive care to these complex patients. When necessary for separate providers to perform the vision and vestibular therapies in the management of $\mathrm{mTBI}$, these health care professionals should be in constant communication and collaborate on the plan of care, as the timing in which visual and vestibular interventions are introduced is imperative.

There is limited research regarding parameters for treating vestibulo-ocular PCD. This case study outlines the parameters adopted by a concussion clinic equipped with a physical therapist trained in vision and vestibular therapy treating an average of 200 unique concussion patients per year (Figure 3). The authors have identified favorable outcomes with early initial therapy focusing on the cervical spine and BPPV until the 3 week point and continued as necessary. They recommend vision therapy is initiated three

(C) The Internet Journal of Allied Health Sciences and Practice, 2019 
weeks post injury with initial emphasis on oculomotor control followed by vergences. Using this method, individuals reach points of meaningful recovery more quickly without the increase in symptoms which can be provoked by early vestibular rehabilitation. One study supports the protocol adopted by the authors and integration of early vision therapy, as binocular vision is necessary to perform vestibular rehabilitation and function in society. ${ }^{39}$

Initially, vestibular rehabilitation should include traditional balance training (substitution). Progression to vestibular provoking and the integration of visuo-vestibular interventions should not occur until improvements in oculomotor control and endurance have been made (Figure 3). Factors necessary to consider before initiating more advanced vision and vestibular interventions are: time since initial injury (at least 3 weeks); cervical limitations such as range of motion (20-40degrees rotation), pain, and post-operative restrictions; low-level therapy tolerance e.g., symptoms for headache, dizziness, and nausea not increasing >2-3/10; presence of vertigo; and degree of oculomotor control. 17,31,38

Limitations to this study include the subjectivity of balance assessments and the subjective nature of symptoms in mTBI. There is also limited research regarding the most effective and efficient training parameters for vision and vestibular therapy for vestibuloocular PCD. 27,39,40 Future research should focus on determining appropriate frequency, intensity, time, and type of rehabilitation that will most effectively and efficiently manage symptoms experienced with protracted recovery from $\mathrm{mTBI}$. This study attempts to provide initial guidelines as seen in Figure 3. Future studies should also examine the prevalence of learning difficulties and attention deficit disorder in individuals with protracted recovery who did not receive vision therapy following mTBI compared to those who did. Finally, studies with long-term follow-up are needed to determine the longevity of effects of vision therapy and determine whether neuroplastic changes are maintained with or without a long-term HEP.

\section{CONCLUSION}

The outcome of this retrospective case study supports the primary purpose of the study, where the integrated vision and vestibular therapy demonstrated to be an effective intervention for an individual with vestibulo-ocular post-concussion disorder. Further, this case study suggests and details a recommended preliminary timeframe for vision therapy followed by the integration of visual and vestibular rehabilitation to more effectively manage persistent $\mathrm{mTBI}$ symptoms and return the patient to prior level of function. 


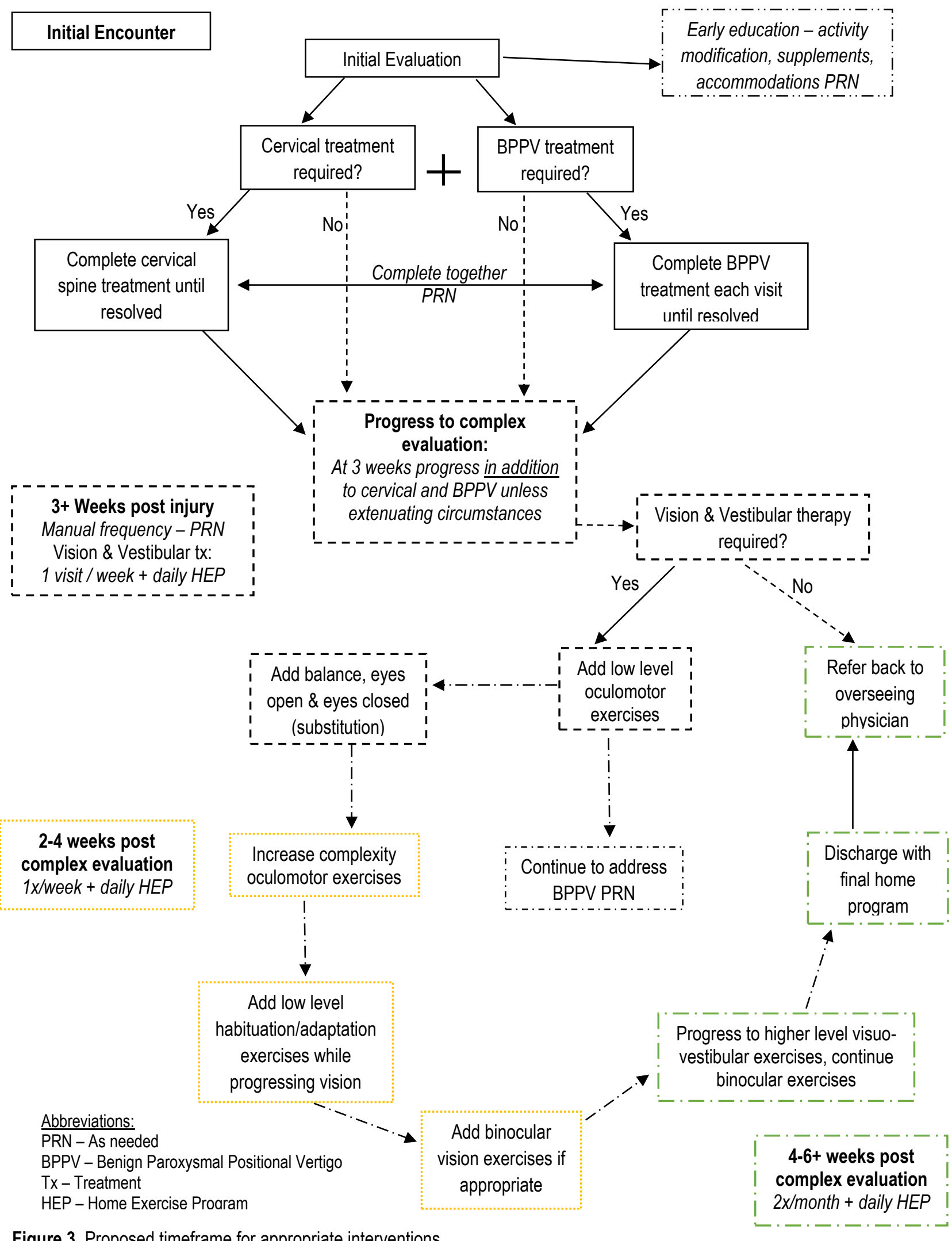

Figure 3. Proposed timeframe for appropriate interventions. 


\section{References}

1. Centers for Disease Control and Prevention [Internet]. Traumatic Brain Injury \& Concussion. Updated January 22, 2016. [Cited 2017 March 15] Available from: https://www.cdc.gov/traumaticbraininjury/data/rates.html.

2. Leddy JJ, Baker JG, Willer B. Active Rehabilitation of Concussion and Post-concussion Syndrome. Phys Med Rehabil Clin N Am. 2016;27(2):437-454

3. Gessel LM, Fields SK, Collins CL, Dick RW, Comstock RD. Concussion Among United States High School and Collegiate Athletes. J Athl Train. 2007;42(4):495-503.

4. Ellis MJ, Leddy JJ, Willer B. Physiological, vestibulo-ocular and cervicogenic post-concussion disorders: An evidencebased classification system with directions for treatment. Brain Inj. 2005;29(2):238-248.

5. Grabowski P, Wilson J, Walker A, Enz D, Wang S. Multimodal impairment-based physical therapy for the treatment of patients with post-concussion syndrome: A retrospective analysis on safety and feasibility. Phys Ther Sport. 2017;23:22-30.

6. Master Cl, Scheiman M, Gallaway M, Goodman A, Robinson RL, Master SR, et al. Vision Diagnoses Are Common After Concussion in Adolescents. Clin Ped. 2016;55(3):260-267.

7. Ventura RE, Jancuska JM, Balcer LJ, Galetta SL. Diagnostic Tests for Concussion: Is Vision Part of the Puzzle? J Neuroopthalmol. 2015;35(1):73-81.

8. McCrory P, Meeuwisse WH, Aubry M, Cantu B, Dvorak J, Echemendia RJ, et al. Consensus Statement on Concussion in Sport: The $4^{\text {th }}$ International Conference on Concussion in Sport, Zurich, November 2012. J Athl Train. 2012;48(4):554-575.

9. Ellemberg D, Henry LC, Macciocchi SN, Guskiewicz KM, Broglio SP. Advances in Sport Concussion Assessment: From Behavioral to Brain Imaging Measures. J Neurotrauma. 2009;26(12):2365-82.

10. Giza CC, Kutcher JK, Ashwal S, Barth J, Getchius TS, Gioia GA, et al. Summary of evidence-based guideline update: Evaluation and management of concussion in sports. Am Acad Neurol. 2013;80(24):2250-7.

11. Ventura RE, Balcer LJ, and Galetta SL. The Concussion Toolbox: The Role of Vision in the Assessment of Concussion. Semin Neurol. 2015;35(05):599-606.

12. Sussman ES, Ho AL, Pendharkar AV, Ghajar J. Clinical evaluation of concussion: the evolving role of oculomotor assessments. Neurosurg Focus. 2016;40(4).

13. Alvarez TL, Kim EH, Vicci VR, Dhar SK, Biswal BB, Barrett AM. Concurrent vision dysfunctions in convergence insufficiency with traumatic brain injury. Optom Vis Sci. 2012;89(12):1740-1751.

14. Scheiman, Mitchell. Understanding and Managing Vision Deficits: A Guide for Occupational Therapists. $2^{\text {nd }}$ ed. Thorofare, NJ. Slack Inc; 2002.

15. Kapoor N, Ciuffreda KJ, Han Y. Oculomotor rehabilitation in acquired brain injury: a case series. Arch Phys Med Rehabil. 2004;85:1667-1678.

16. Gurr B, Moffat N. Psychological consequences of vertigo and the effectiveness of vestibular rehabilitation for brain injury patients. Brain Inj. 2001;15(5):387-400.

17. Alsalaheen B, Mucha A, Morris LO, Whitney SL, Furman JM, Camiolo-Reddy CE, et al. Vestibular rehabilitation for dizziness and balance disorders after concussion. J Neurol Phys Ther. 2010;34(2):87-93.

18. Leddy JJ, Baker JG, Kozlowski K, Bisson L, Willer B. Reliability of a Graded Exercise Test for Assessing Recovery from Concussion. Clin J Sport Med. 2011;21(2):89-94.

19. Kozlowski KF, Graham J, Leddy J, Devinney-Boymel L, Willer BS. Exercise Intolerance in Individuals With Postconcussion Syndrome. J Athl Train. 2013;48(5):627-635.

20. Ellis MJ, Cordingley DM, Vis S, Reimer KM, Leiter J, Russell K. Clinical predictors of vestibulo-ocular dysfunction in pediatric sports-related concussion. J Neurosurg Pediatr. 2017;19(1):38-45.

21. Rehab Measures (internet). Activities- Specific Balance Confidence Scale. Updated 2013. [Cited 2018, February 8]. Available from: https://www.sralab.org/rehabilitation-measures/activities-specific-balance-confidence-scale.

22. Rehab Measures [Internet]. Dizziness Handicap Inventory. Updated 2014. [Cited 2017, March 29]. Available from: http://www.rehabmeasures.org/Lists/RehabMeasures/DispForm.aspx?ID=1041.

23. Borsting EJ, Rouse MQ, Mitchell LG, Scheiman M, Cotter SA, Cooper J, et al. Validity and Reliability of the Revised Convergence Insufficiency Symptom Survey in Children Aged 9 to 18 Years. Optom Vis Sci. 2003;80(12):832-8.

24. APTA Neurology Section [Internet]. TBI EDGE outcome measures for in- and outpatient rehabilitation. Published 2013. [Cited 2017, March 29]. Available from: http://www.neuropt.org/professional-resources/neurology-section-outcomemeasures-recommendations/traumatic-brain-injury. 
25. Lau BC, Collins MW, Lovell MR. Sensitivity and Specificity of Subacute Computerized Neurocognitive Testing and Symptom Evaluation in Predicting Outcomes After Sports-Related Concussion. Am J Sports Med. 2011;39(6):12091216.

26. Scheiman M, Cotter S, Kulp MT, Mitchell GL, Cooper J, Gallaway M, et al. Treatment of accommodative dysfunction in children: results from a randomized clinical trial. Optom Vis Sci. 2011;88(11):1343-1352.

27. Scheiman M, Mitchell GL, Cotter S, Kulp MT, Cooper J, Rouse M, et al. A randomized clinical trial of vision therapy/orthoptics versus pencil pushups for the treatment of convergence insufficiency in young adults. Optom Vis Sci. 2005; 82(7):583-595.

28. Gallaway M, Scheiman M, Mitchell LG. Vision Therapy for Post-Concussion Vision Disorders. Optom Vis Sci. 2017;94(1): 68-73.

29. Skop, K. Traumatic Brain Injury and Concussions: An Advanced Vestibular-Balance Course. 2015 June 27-28; Las Vegas, NV: North American Seminars Inc.

30. Amster D. When Stress Strains Vision. Review of Optometry Website. Published 2011. [Cited 2017, March 29]. Available from: https://www.reviewofoptometry.com/article/when-stress-strains-vision.

31. Amin MS. Vestibuloocular Reflex Testing [Internet]. Medscape c1994-2018. Published 2016. [Cited 2017 March 29]. Availabe from: http://emedicine.medscape.com/article/1836134-overview.

32. Herdman SJ, Tusa RJ, Blatt P, Suzuki A, Venuto PJ, Roberts D. Computerized Dynamic Visual Acuity Test in the Assessment of Vestibular Deficits. Am J Otol. 1998;19(6):790-796.

33. Riska KM, Hall CD. Reliability and Normative Data for the Dynamic Visual Acuity Test for Vestibular Screening. Otol \& Neurol. 2016;37(5):545-552.

34. Baker JG, Freitas MS, Leddy JJ, Kozlowski KF, Willer BS. Return to Full Functioning after graded Exercise Assessment and Progressive Exercise Treatment of Postconcussion Syndrome. Rehabil Res Pract. 2012;2012:705309.

35. Makdissi M, Cantu RC, Johnston KM, McCrory P, Meeuwisse WH. The difficult concussion patient: what is the best approach to investigation and management for persistent (>10 days) postconcussive symptoms? Br J Sports Med. 2013;47(5):308-13.

36. Thiagarajan $\mathrm{P}$, Ciuffreda KJ. Effect of oculomotor rehabilitation on vergence responsivity in mild traumatic brain injury. J Rehabil Res Dev. 2013;50:1223-1240.

37. Scheiman M, Gwiazda J, Li T. Non-surgical interventions for convergence insufficiency. Cochrane Database Syst Rev. 2011;(3):CD006768.

38. Kontos AP, Deitrick JM, Collins MW, Mucha A. Review of Vestibular and Oculomotor Screening and Concussion Rehabilitation. J Athl Train. 2017;52(3):256-261.

39. Kapoor N, Ciuffreda KJ, Han Y. Oculomotor rehabilitation in acquired brain injury: a case series. Arch Phys Med Rehabil. 2004;85:1667-1678.

40. Scheiman M, Wick B. Clinical Management of Binocular Vision: Heterophoric Accommodative and Eye Movement Disorders. $4^{\text {th }}$ ed. Philadelphia: Lippincott Williams \& Wilkins; 2014. 